\title{
LA REFORMA DE LA LRU
}

\section{LRU REFORM}

\section{AUTORES}

Juan José Ugalde Fernández: Profesor de Relaciones Públicas de la Facultad de Ciencias de la Información de la Universidad Complutense de Madrid (España). juan.jose@arrakis.es

\section{CURRÍCULUM VITAE}

Profesor de Relaciones Públicas de la Facultad de Ciencias de la Información de la Universidad Complutense de Madrid (España). Autor de varios artículos sobre la reforma de la ley de enseñanza superior en España, conferenciante y ponente en numerosos congresos universitarios y especialista en comunicación corporativa.

\section{RESUMEN}

Aunque el Ministro Rajoy ha declarado que reformará la situación del profesorado antes de cambiar la LRU, por ahí circula un proyecto de ley de modificación de la misma que conviene que conozcamos.

Según el diario EL PAIS, en su versión electrónica, el Ministro tiene prevista una apretada agenda de modificaciones, antes de ponerse a reformar en profundidad la obsoleta LRU (Obsoleta porque nadie creyó en su aplicación y se pusieron todos los medios para que fuera ineficaz). 


\section{PALABRAS CLAVE}

Reforma - LRU - Ley Orgánica

\section{ABSTRACT}

Although the Minister Rajoy said that will reform the situation of teachers before changing the LRU, circulates around a bill to amend the same as it is to know.

The newspaper El Pais, in its electronic version, the Minister has planned a busy schedule of modifications made before a thorough reform the outdated LRU (obsolete because no one believed in its application and got every means to make it ineffective) .

\section{KEY WORDS}

Reforma - LRU - Law

\section{ÍNDICE}

La reforma de la LRU

1. Proyecto de ley por la que se modifica parcialmente la Ley Orgánica 11/1983 de 25 de agosto, de Reforma Universitaria

1.1. Disposiciones adicionales

1.2. Disposiciones transitorias

1.3. Disposición derogatoria

1.4. Disposiciones finales 


\section{La reforma de la LRU}

Aunque el Ministro Rajoy ha declarado que reformará la situación del profesorado antes de cambiar la LRU, por ahí circula un proyecto de ley de modificación de la misma que conviene que conozcamos.

Según el diario EL PAIS, en su versión electrónica, el Ministro tiene prevista una apretada agenda de modificaciones, antes de ponerse a reformar en profundidad la obsoleta LRU (Obsoleta porque nadie creyó en su aplicación y se pusieron todos los medios para que fuera ineficaz).

Por ejemplo, el ministro negociará la modificación de las enseñanzas de humanidades.

SUSANA PÉREZ DE PABLOS , Madrid (23-02-99) escribía en el citado diario:

"Una de las principales reclamaciones de las universidades, la de regular la precaria situación del profesorado universitario, es la cuestión más relevante que abordará el ministro de Educación, Mariano Rajoy, en el escaso plazo del que dispone antes de que acabe la legislatura.

Rajoy se comprometió la pasada semana, en su primera comparecencia ante la Comisión de Educación del Congreso, a impulsar primero esta medida y abordar "a medio plazo" cambios más profundos en la Ley de Reforma Universitaria (LRU).

En un apresurado repaso a su agenda, el ministro explicó sus planes para este año, que fueron tachados de poco concretos por la oposición. Rajoy hizo un insistente llamamiento al consenso con los sectores implicados en cada área, como condición imprescindible para sacar las reformas adelante. Éstos son sus planes: 
-- LRU. Potenciar el funcionamiento del Consejo de Universidades. Favorecer la movilidad de los estudiantes, abriendo los distritos universitarios y ampliando las becas y ayudas, y la de los profesores, buscando fórmulas de contratación más estables para el profesorado contratado. Impulsar formas de financiación con las comunidades autónomas y programas de investigación, de becas y de cooperación internacional.

-- Humanidades. No descarta Rajoy impulsar la reforma de las humanidades que pretendía realizar su antecesora en el cargo, Esperanza Aguirre, modificando la secundaria y el bachillerato. Convocar a la Conferencia Sectorial de Educación para establecer las medidas que modifiquen las enseñanzas de humanidades en la línea marcada en el dictamen de la Comisión de Humanidades, que presidió Juan Antonio Ortega y Díaz-Ambrona.

-- Traspasos. Culminar los traspasos de las competencias educativas a las seis comunidades autónomas pendientes antes de que finalice la legislatura. Rediseñar el área de educación del ministerio para la nueva situación. Lograr que el ministerio asegure la unidad básica del sistema educativo.

-- Becas. Aumentar el dinero que destina el Estado para financiar becas. Crear un nuevo modelo de gestión de becas "en el que se aplique el principio de descentralización de la gestión a partir de las normas básicas que dicte el Estado". Dedicar atención preferente a las becas como instrumento para hacer afectivo el principio de la igualdad al acceso y continuidad de los estudios de los alumnos.

-- Educación primaria. Conseguir la escolarización plena a los 3 años. Incrementar las plantillas de especialistas en educación primaria, reducir el número de alumnos por aula (actualmente, de 20 de media, según Rajoy) y la relación media de alumnos por 
profesor (actualmente, de 19). Potenciar la enseñanza de idiomas, incluido en los cursos en los que no es obligatoria, y ampliar la red de centros para acercarlos al domicilio de las familias. Poner en funcionamiento el próximo curso 24 nuevos colegios.

-- Educación secundaria. Aumentar en un 10\% el actual ritmo de traslado del primer ciclo de la ESO a los institutos de secundaria (el 52\% de los alumnos ya estudian en ellos) "respetando la situación de las zonas rurales en las que los estudiantes estén mejor atendidos en los centros de primaria". Poner en funcionamiento el próximo curso 44 institutos de educación secundaria.

-- Formación Profesional. Informar a los alumnos y a los padres de toda la oferta de ciclos formativos de formación profesional que existen y que ha aumentado este curso en un $10 \%$. Aumentarla el próximo curso en un 16\%. Tomar medidas para facilitar a los alumnos el paso del ciclo del grado medio de FP al de grado superior y de éste al universitario.

-- Crear el Instituto Nacional de Cualificaciones, que hará un estudio de los campos profesionales para adecuar los estudios a las demandas reales de trabajo, implicando en ello a todos los sectores."

Y he aquí el texto del

1. Proyecto de ley por la que se modifica parcialmente la Ley Orgánica 11/1983 de 25 de agosto, de Reforma Universitaria

Exposición de Motivos 
1. La Ley Orgánica 11/1983 de 25 de agosto, de Reforma Universitaria inició un proceso de reordenación general de la Universidad española contemporánea. A partir de un modelo basado en la consideración de las Universidades como meros anejos del departamento ministerial correspondiente expresó la opción por otro sistema cuyo centro de gravedad se encuentra en la autonomía universitaria, en correcto desarrollo de lo dispuesto en el apartado 10 del artículo 27 de la Constitución. Este cambio provocó, como no podía ser menos transformaciones substanciales de todos los aspectos del régimen jurídico universitario, desde su gobierno hasta el estatuto de las Universidades privadas pasando por el contenido y régimen de las enseñanzas o las Administraciones competentes.

Transcurridos quince años desde la promulgación de la Ley que lo puso en marcha, el proceso aparece hoy en fase de madurez. Se ha completado el mapa universitario, ya que es poco probable la creación de nuevas Universidades públicas; ha finalizado el proceso de transferencia de competencias a las Comunidades Autónomas y se ha ultimado el proceso de transformación de las enseñanzas universitarias.

2. A la vista de esta evolución, es legítimo el debate acerca de si el sistema instaurado por la Ley de Reforma Universitaria merece pasar inalterado al siglo XXI o si, por el contrario, han de emprenderse cambios en el mismo a la vista de la experiencia acumulada en la aplicación de la ley. Esta Ley se basa en la convicción de que es tiempo de reformas parciales fundadas en la experiencia y no de revoluciones hacia lo desconocido. Y es que no puede olvidarse que el momentum que vio nacer la Ley de Reforma Universitaria fue constituyente y, por tanto, excepcional. Ni la experiencia ni las circunstancias aconsejan someter a nuestro sistema universitario a una alteración substancial de las bases sobre las que se asienta. Los tiempos aconsejan reformas prudentes más que cambios totales siempre rodeados de incertidumbre. 
3. Por esta razón, esta Ley que ahora se presenta adopta una vía intermedia. Si bien se abandona cualquier pretensión de cambio general no se renuncia por ello a mejorar nuestro sistema de educación superior. Los quince años de aplicación de la Ley han generado un consenso importante en la comunidad universitaria y en la sociedad civil acerca de la necesidad de revisar determinados aspectos de la regulación contenida en la Ley. Tal consenso es especialmente claro en lo que se refiere al régimen jurídico del profesorado.

4. La aplicación de la Ley de Reforma Universitaria de 1983 ha puesto al descubierto tres conjuntos de problemas fundamentales en este ámbito.

En primer lugar, problemas relativos a la selección del profesorado provocando fenómenos que se han denominado, en el debate público, de "endogamia" universitaria y creando un estado de opinión crítico respecto de su plena conformidad con los criterios de mérito y capacidad que, por imperativo constitucional, han de presidir el acceso a la función pública.

En segundo lugar, un problema histórico de nuestros profesores universitarios como es el de la precariedad de su estatuto no ha podido resolverse a pesar de haberse sucedido los intentos en tal sentido.

En tercer lugar, las Comunidades Autónomas que, de acuerdo con sus Estatutos, ostentaban amplias competencias en materia universitaria, carecían de los instrumentos jurídicos adecuados para ejercitar sus competencias, dada la opción legislativa basada casi exclusivamente en el carácter funcionarial del profesorado y la consiguiente y necesaria uniformidad de su régimen.

5. La reforma que encarna esta Ley trata de dar solución a los tres problemas que se acaban de describir. Es decir, garantiza en el mayor nivel posible la vigencia efectiva de los principios de mérito y capacidad en la selección del profesorado universitario; crea los instrumentos adecuados para resolver el problema de la precariedad de los profesores no funcionarios y proporciona a las Comunidades 
Autónomas los medios jurídicos adecuados para que puedan ejercer las competencias que, en materia universitaria, les atribuye el bloque de constitucionalidad.

1. El sistema de selección del profesorado funcionario establecido en la Ley que ahora se modifica ha producido algunos resultados insatisfactorios. Aunque mejoró notablemente la valoración de la actividad investigadora de los candidatos, redujo - en comparación con el sistema clásico de oposiciones - la presión competitiva del proceso de selección. La excesiva presencia del componente local en la comisión juzgadora y la escasa capacidad discriminadora de las pruebas de selección han dificultado la realización del proceso con los mayores niveles posibles de competencia docente e investigadora.

2.Con esta pretensión, esta ley realiza una modificación relevante de la composición de las comisiones juzgadoras estableciendo que cuatro de sus cinco miembros sean designados por el sistema de sorteo y lo sean entre profesores de igual o superior rango administrativo de distintas y diferentes universidades. Se garantiza así que la influencia del elemento local sobre la composición de la comisión se mantenga en niveles razonables y que ninguna Universidad pueda tener una presencia excesiva en la misma.

3.En segundo lugar, se modifica el contenido de las pruebas en los concursos para plazas de profesor titular de Universidad, catedrático y profesor titular de Escuela Universitaria ampliando el número mínimo de pruebas - que pasa de dos a tres y garantizando el conocimiento de la asignatura por parte de los candidatos mediante la inserción de un ejercicio consistente en la exposición pública de un tema del programa presentado entre los que, determinados mediante sorteo, elija 
la comisión juzgadora. Se atiende así a una crítica del sistema actual muy extendida en la comunidad universitaria. Además, se asegura la aptitud de los candidatos mediante la adición de una prueba de carácter práctico, cuya ausencia en el sistema vigente resulta clamorosa por comparación con el acceso a cualquier otra posición de funcionario en la Administración Pública. Entendiendo que los que concursan a una plaza de Catedrático de Universidad habrán debido pasar, necesariamente y salvo casos excepcionales, por una prueba semejante, no se ha considerado conveniente introducir cambios en las pruebas de acceso a este cuerpo de funcionarios, respecto del cual, debe evaluarse, esencialmente el curriculum docente e investigador y su capacidad para realizar aportaciones científicas originales. No obstante, el texto deja abierta la posibilidad de que, en el futuro, y si las circunstancias lo aconsejan, se amplíe también el número de pruebas para el acceso al cuerpo de catedráticos de Universidad.

III

1. Otra de las modificaciones fundamentales que pretende introducir esta Ley se refiere a las vías de acceso a la condición de profesor universitario. Como se ha expuesto, la única vía que permite adquirir la condición de profesor estable de una Universidad española es, hoy por hoy, la de los concursos para profesor funcionario. Las consecuencias no se han dejado esperar y se han manifestado de forma particularmente grave. Las Universidades han utilizado la única vía de contratación disponible - la del profesorado asociado - para cubrir sus necesidades docentes en una forma impensable en la época en la que se elaboró la Ley de Reforma Universitaria.

La figura del profesor asociado, pensada para incorporar a la Universidad a los profesionales que como actividad accesoria desearan prestar sus servicios a la docencia superior se ha convertido, de hecho, en la forma normal de contratación de manera que el número de profesores asociados - muchos de ellos a tiempo 
completo - se cuente por decenas de miles en toda España en contra, si no de la letra, sí de la intención original del legislador. Una Universidad en la que una buena parte de su personal docente depende de un contrato renovable año a año resulta un escenario inaceptable. Esta Ley contiene la primera regulación que, cuando menos, puede calificarse de realista: reserva la figura del profesor asociado para cumplir los objetivos que presidieron su introducción en la legislación universitaria española, pero proporciona a las Universidades una vía alternativa para contratar profesores. Una vía que, por otra parte, no renuncia a asegurar un escrupuloso respeto a los principios de mérito y capacidad..

2. Estos dos objetivos quedan reflejados en el texto articulado de esta Ley mediante la creación de las figuras del Profesor Colaborador y del Profesor Contratado Doctor. La primera figura permitirá contratar de forma estable a los docentes no doctores. La segunda, dará estabilidad a los docentes que, siendo doctores, no quieran o no puedan acceder a los cuerpos de funcionarios docentes. La suficiencia y flexibilidad del sistema derivan del hecho de que la Ley permite que hasta la mitad del profesorado de una Universidad esté formado por profesores de estos tipos al establecerse como límite cuantitativo el derivado de la garantía de que la mayoría del profesorado será funcionario. Dentro de tal límite, el empleo de estas figuras permitirá a las Comunidades Autónomas - que, conforme a la Ley tienen la competencia para su regulación - y a las Universidades desarrollar su propia política de profesorado, en consonancia con el respeto, al principio de autonomía. Por otra parte, la necesidad de una evaluación externa de los candidatos, a cargo de un organismo independiente, y la publicidad de carácter nacional que es requisito necesario de la formalización de estos contratos aseguran un alto nivel de transparencia en los correspondientes procesos de selección. 
3. La posibilidad de contratar de forma estable a doctores e investigadores incentivará, sin duda, la tan necesaria movilidad del profesorado. En la misma línea de intenciones se mueve la obligación que se impone a las Universidades de determinar, en Junta de Gobierno, las plazas vacantes que serán cubiertas necesariamente a través de concurso de méritos, concurso al que pueden acudir, lógicamente, profesores del cuerpo al que corresponda la vacante y que deseen profesar en la Universidad convocante o que se hallen en excedencia o en servicios especiales.

IV

La tercera modifica trascendente que introduce la presente ley se refiere a la participación de las Comunidades Autónomas. Como se ha expuesto, la formulación original de la Ley de Reforma Universitaria no podía tener en cuenta un proceso de transferencias que, iniciado en la segunda mitad de los años ochenta, ha atribuido a las Comunidades Autónomas las competencias de gestión y financiación del sistema universitario. Esta Ley trata de reducir la discrepancia entre instrumentos normativos y financieros atribuyendo a las Comunidades Autónomas la competencia para regular las figuras y el régimen jurídico del profesorado contratado, lo que parece plenamente justificado en la medida en que serán las Comunidades Autónomas las que habrán de financiar las políticas de profesorado que se lleven a cabo utilizando estas figuras. Se trata, pues y simplemente, de un caso más de aplicación del principio según el cual debe ser la autoridad que financia la que establezca las condiciones que obligan al gasto. No hay alteración alguna en el reparto competencial, manteniéndose para el Estado la plenitud de las competencias propias en materia de funcionarios de cuerpos nacionales, el ejercicio de la función de Alta inspección y la competencia genérica en materia de coordinación del sistema universitario. 
El resto de la regulación contenida en la presente Ley tiene un carácter marcadamente técnico y se compone de mejoras textuales o adaptaciones de otras normas a los nuevos tipos de profesores. También se ha incluido un importante conjunto de disposiciones transitorias.

VI

En definitiva, esta nueva versión del Título V de la Ley 11/1983 supone el encaje de una importante pieza en el proceso de modernización de la Universidad española. Se ha producido tras un amplísimo debate en el que han participado las Comunidades Autónomas, las autoridades académicas y, especialmente el Consejo de Universidades. Combina la resolución de un problema histórico de precariedad de un amplio sector del profesorado universitario con una flexibilidad real para que las Universidades puedan seleccionar el mejor "capital humano" con vocación docente e investigadora. Se abre, además, un camino nuevo a los jóvenes doctores e investigadores españoles por medio de un proceso más objetivo y flexible de acceso a la carrera docente. Todo ello en un marco mínimamente reglamentista y en el que se reconoce el protagonismo debido a dos actores principales de la educación superior en España -las Universidades y las Comunidades Autónomas- manteniendo, con plena vigencia, el ejercicio de las importantes funciones que corresponden al Estado.

Artículo único. Extensión de la modificación.

Los artículos y disposiciones de la Ley Orgánica 11/1983, de Reforma Universitaria, que a continuación se relacionan y los que se añaden a la misma, quedan redactados en los términos que, en cada caso, se indican: 
1. Los números 1 y 3 del artículo 33 y los números 4, 5, 6 y 7 que se añaden al mismo quedan redactados como sigue:

"1. El profesorado funcionario de las Universidades estará constituido por los siguientes Cuerpos docentes:

a. Catedráticos de Universidad.

b. Profesores Titulares de Universidad.

c. Catedráticos de Escuelas Universitarias.

d. Profesores Titulares de Escuelas Universitarias.

3. No obstante lo establecido en el apartado 1 de este artículo, las Universidades podrán contratar en régimen administrativo y en las condiciones y según el procedimiento que se establezcan en la normativa de la Comunidad Autónoma correspondiente y en los Estatutos, y dentro de sus previsiones presupuestarias. Profesores Asociados, Profesores Contratados Doctores y Profesores Colaboradores. El número total de unos y otros no podrá superar el número de profesores pertenecientes a los cuerpos de funcionarios docentes de cada Universidad, que deberán ser mayoritarios.

4. Los Profesores Asociados serán contratados a tiempo parcial entre especialistas de reconocida competencia que desarrollen normalmente su actividad profesional fuera de la Universidad.

5. Los Profesores Contratados Doctores serán seleccionados mediante concursos públicos, a los que se dará publicidad efectiva en todo el territorio nacional, convocados por la respectiva Universidad y resueltos por Comisiones cuya composición será determinada conforme a lo establecido en el apartado 3 anterior, entre quienes posean el título de Doctor y siempre que, como mínimo, 
reciban evaluación positiva externa del historial investigador $\mathrm{y}$, en su caso, docente, por el órgano de evaluación que determine el Gobierno.

La duración de estos contratos será de cuatro años, renovables sin limitación temporal. La renovación o renovaciones se condicionarán a la evaluación externa del rendimiento investigador y docente, en los términos previstos en el párrafo anterior.

Las Comunidades Autónomas podrán determinar, en su caso, los niveles académicos y de gestión que correspondan a las eventuales categorías de Profesores Contratados Doctores, los cuales no podrán, sin embargo, ostentar el cargo académico de Rector. Los cargos académicos de Decano de Facultad, Director de Escuela Técnica Superior, Escuela Universitaria o Departamento universitario podrá ser desempeñados por los Profesores Contratados Doctores, de no haber candidato con la categoría de Catedrático ni de Profesor Titular, de acuerdo con lo dispuesto en los Estatutos de la Universidad.

6. Los Profesores Colaboradores serán seleccionados mediante concursos públicos, a los que se dará publicidad efectiva en todo el territorio nacional, convocados por la respectiva Universidad y resueltos por Comisiones cuya composición será determinada conforme a lo establecido en el apartado 3 anterior, entre Licenciados, Arquitectos o Ingenieros y, en las áreas específicas a que se refiere el artículo 35 entre Diplomáticos, Arquitectos Técnicos e Ingenieros Técnicos, para impartir materias o créditos determinados. La duración de estos contratos será la que fije la Comunidad Autónoma correspondiente.

En todo caso, transcurridos cuatro años, las eventuales renovaciones del contrato requerirán evaluación positiva externa de la labor realizada en los términos previstos en el párrafo segundo del apartado anterior. La evaluación positiva permitirá igualmente su contratación como Profesores Contratados Doctores o Ayudantes. 
7. Las Universidades podrán igualmente contratar Profesores Visitantes entre profesores o investigadores procedentes de otras Universidades y centros de investigación, españoles y extranjeros y Profesores Eméritos."

2. Los números 1, 2, 3 y 5 del artículo 34 quedan redactados de la forma siguiente:

" 1. La Universidad podrá contratar ayudantes en los términos de la presente Ley, en los que en su desarrollo dicten las Comunidades Autónomas y en los que se establezcan en los respectivos Estatutos. Su actividad estará orientada a completar su formación científica, pero también podrán colaborar en tareas docentes en los términos previstos en la normativa implicable y los Estatutos de la Universidad.

2. La contratación de los ayudantes tendrá lugar mediante concursos públicos, a los que se dará publicidad efectiva en todo el territorio nacional, convocados por la respectiva Universidad y resueltos por Comisiones, cuya composición será determinada por los Estatutos.

3. Los ayudantes de Facultades y Escuelas Técnicas Superiores serán contratados con dedicación a tiempo completo por un plazo máximo de tres años, entre quienes tras finalizar los cursos de doctorado a que se refiere el artículo 31 acrediten, además, un mínimo de dos años de actividad investigadora. Estos contratos serán renovables una sola vez, por un plazo máximo de tres años, siempre que el ayudante hubiera obtenido el título de Doctor.

5. Con adscripción a las áreas específicas a que se refiere el artículo 35, las Universidades podrán contratar ayudantes de Escuelas Universitarias entre quienes estén en posesión del título de Licenciado, Arquitecto, Ingeniero 
Superior, Diplomado, Arquitecto Técnico o Ingeniero Técnico. El contrato, en este caso, será por tres años, renovable por un plazo máximo de otros dos."

3. Los números 1, 2 y 3 del artículo 35 y el número 4 que se añade al mismo, quedan redactados de la forma siguiente:

" 1. En las áreas específicas señaladas por el Consejo de Universidades podrán convocarse plazas de Profesor Titular de Escuelas Universitarias. Para poder concursar a las mismas, será necesario estar en posesión del título de Licenciado, Arquitecto, Ingeniero, Diplomado, Arquitecto Técnico o Ingeniero Técnico.

2. Los concursos serán convocados por la Universidad correspondiente y publicados en el "Boletín Oficial del Estado" y en el boletín Oficial de la Comunidad Autónoma que corresponda.

3. Los concursos serán resueltos por Comisiones juzgadoras compuestas por cinco profesores del área de conocimiento a que corresponda la plaza. El presidente será un Catedrático de Escuelas Universitarias o un Catedrático de Universidad, nombrado por la Universidad convocante en el modo previsto en los Estatutos de la misma. Los cuatro miembros restantes, igualmente nombrados por la Universidad convocante, serán designados mediante sorteo, según el procedimiento que reglamentariamente fije el Gobierno, entre profesores de los cuerpos docentes universitarios, todos ellos de Universidad diferente y distinta a la convocante.

4. Los concursos se celebrarán en sesión pública y comprenderán al menos tres pruebas: una consistirá en la presentación y discusión con la Comisión de una memoria, que incluirá un proyecto docente e investigador, y los méritos docentes e investigadores del candidato; otra consistirá en la exposición pública de un 
tema del programa presentado por el candidato, a elección de la Comisión, de entre los preseleccionados por sorteo; otra tendrá carácter práctico."

4. Los números 1, 2 y 3 del artículo 36 y el número 4 que se añade al mimo quedan redactados como sigue:

" 1. Para poder concursar a plazas de Catedrático de Escuelas Universitarias, será necesario estar en posesión de título de Doctor.

2. Los concursos serán convocados por la Universidad correspondiente y publicados en el "Boletín Oficial del Estado" y en el Boletín Oficial de la Comunidad Autónoma que corresponda.

3. Los concursos serán resueltos por comisiones juzgadoras compuestas por cinco profesores del área de conocimiento a que corresponda la plaza. El presidente será un Catedrático de Universidad, nombrado por la Universidad convocante, en el modo previsto en los Estatutos de la misma. Los cuatros miembros restantes, igualmente nombrados por la Universidad convocante, serán designados mediante sorteo, según el procedimiento que reglamentariamente fije el gobierno, entre Catedráticos de Escuelas Universitarias, Profesores Titulares de Universidad y Catedráticos de Universidad, todos ellos de Universidad diferente y distinta a la convocante.

4. Los concursos se celebrarán en sesión pública y comprenderán al menos tres pruebas, en los términos señalados en el apartado 4 del artículo 35.

5. Los números 2, 3 y 4 del artículo 37 quedan redactados en la siguiente forma: 
"2. Los concursos serán convocados por la Universidad correspondiente y publicados en el "Boletín Oficial del Estado" y en el Boletín Oficial de la Comunidad Autónoma que corresponda.

3. Los concursos serán resueltos por comisiones juzgadoras compuestas por cinco profesores del área de conocimiento a que corresponda la plaza. El presidente será un Catedrático de Universidad, nombrado por la Universidad convocante, en el modo previsto en los Estatutos de la misma. Los cuatros miembros restantes, igualmente nombrados por la Universidad convocante, serán designados mediante sorteo, según el procedimiento que reglamentariamente fije el Gobierno, entre Profesores Titulares de Universidad y Catedráticos de Universidad, todos ellos de Universidad diferente y distinta a la convocante.

4. Los concursos se celebrarán en sesión pública y comprenderán al menos tres pruebas, en los términos señalados en el apartado 4 del artículo 35."

6. Los números 1,2 y 3 del artículo 38 y el número 4 que se añade al mismo quedan redactados como sigue:

" 1. Para poder concursar a plazas de Catedrático de Universidad, será necesario estar en posesión del título de Doctor y ostentar la condición de Catedrático de Universidad, o bien la de Profesor Titular de Universidad o Catedrático de Escuelas Universitarias, en ambos casos con un mínimo de tres años de antigüedad. El Consejo de Universidades podrá eximir el cumplimiento del requisito señalado en el párrafo anterior, a aquellos Doctores, españoles o extranjeros, en quienes concurran méritos extraordinarios que así lo aconsejen. 
2. Los concursos serán convocados por la Universidad correspondiente y publicados en el "Boletín oficial del Estado" y en el Boletín Oficial de la Comunidad Autónoma que corresponda.

3. Los concursos serán resueltos por comisiones juzgadoras compuestas por cinco Catedráticos de Universidad del área de conocimiento a que corresponda la plaza. El presidente será nombrado por la Universidad convocante en el modo previsto en los Estatutos de la misma. Los cuatro miembros restantes, igualmente nombrados por la Universidad convocante, serán designados mediante sorteo, según el procedimiento que reglamentariamente fije el Gobierno, entre Catedráticos de Universidad diferente y distinta a la convocante.

4. Los concursos se celebrarán en sesión pública y constarán al menos de dos pruebas: una consistirá en la presentación y discusión con la Comisión de una Memoria, que incluirá un proyecto docente e investigador, y los méritos docentes e investigadores que presente el candidato: otra consistirá en la presentación y debate con la Comisión de un trabajo original de investigación."

7. El artículo 39 queda redactado como sigue:

" 1. Vacante una plaza de los Cuerpos previstos en el artículo 33, apartado 1, la Universidad decidirá, en el modo que establezcan sus Estatutos, de conformidad con las necesidades docentes e investigadoras de la misma, y previo informe del Consejo Social, de los Departamentos y de los Centros afectados, si procede o no la minoración o el cambio de denominación o categoría de la plaza.

No obstante, cuando el informe de los Departamentos o de los Centros afectados no sea emitido en el plazo fijado por los Estatutos de la Universidad, ésta podrá decidir conforme a lo dispuesto en el párrafo anterior. 
2. Cumplido el trámite a que se refiere el apartado anterior, la Junta de Gobierno, en atención a las necesidades docentes e investigadoras, acordará qué plazas, de las vacantes a las que alude el apartado anterior, serán provistas mediante Concurso de Méritos entre profesores del Cuerpo a que corresponda la vacante.

Las Comisiones juzgadoras de los Concursos de Méritos se constituirán con arreglo a lo que determinen los Estatutos de la Universidad. El Concurso de Méritos consistirá en la presentación y discusión con la Comisión de los méritos e historial académico e investigador del candidato, así como de su proyecto docente y de investigación.

3. Cuando la plaza convocada a Concurso de Méritos sea de Profesor Titular de Universidad o de Catedrático de Escuelas Universitarias, podrán concurrir indistintamente profesores de ambos Cuerpos.

Para determinadas áreas de conocimiento, a juicio de la Universidad, se podrá autorizar que a los Concursos de Méritos contemplados en el apartado 3 anterior, para plazas de Profesor Titular de Escuelas Universitarias, puedan concurrir los Profesores de enseñanza Secundaria que tengan la condición de Catedrático. Lo mismo podrá acordarse para plazas de Profesor Titular de Universidad y Catedrático de Escuelas universitarias, en relación a los Profesores señalados en el inciso anterior que estén en posesión del Título de Doctor.

4. En ningún caso podrá ocuparse interinamente una plaza vacante durante más de un año sin que ésta sea convocada a concurso."

5. Las Universidades podrán convocar los concursos a que se refieren los artículos anteriores siempre que las plazas estén en el estado de gastos de su presupuesto." 
8. El artículo 40 queda redactado como sigue:

"Todos los concursos y procesos selectivos a los que se refieren los artículos anteriores podrán resolverse con la no provisión."

9. El artículo 41 queda redactado como sigue:

1. En los concursos y procesos selectivos a que se refiere la presente Ley quedarán garantizados, en todo momento, la igualdad de condiciones de los candidatos, y el respeto a los principios de mérito, capacidad y publicidad de los mismos.

2. Los procedimientos para la designación de los miembros de las Comisiones se basarán en criterios objetivos y generales, garantizando su idoneidad, competencia científica y objetividad de su actuación.

10. El artículo 42 queda redactado como sigue:

"Las Comisiones a que hacen referencia los artículos 35 a 39 de la presente Ley, propondrán, mediante informe motivado, el nombramiento de candidatos, que en ningún caso podrán exceder al número de plazas convocadas.

Dichos nombramientos serán efectuados por el Rector de la Universidad correspondiente, inscritos en el Registro de Personal de los Cuerpos respectivos y publicados en el "Boletín Oficial del Estado" y en el de la Comunidad autónoma correspondiente."

11. El número 2 del artículo 43 queda redactado como sigue: 
" 2. Esta reclamación será enjuiciada por una Comisión que, presidida por el Rector, se compondrá de seis Catedráticos de Universidad de diversas áreas de conocimiento, con reconocido prestigio docente e investigador, elegidos por el Claustro por un período de cuatro años mediante mayoría absoluta en votación secreta. Si en el plazo de tres meses la Comisión no adoptase decisión alguna, la reclamación se entenderá denegada.

12. Los números 1, 2 y 3 del artículo 45 quedan redactados como sigue:

"1. El profesorado universitario ejercerá sus funciones preferentemente a tiempo completo, o bien a tiempo parcial. La dedicación a tiempo completo será compatible con la realización de las actividades a que se refiere el artículo 11, en los términos que reglamentariamente establezca el Gobierno y, en su caso, las Comunidades Autónomas en lo que respecta al profesorado contratado.

2. La dedicación a tiempo completo es requisito necesario para desempeñar el cargo del Rector. Los Estatutos de las Universidades podrán, además, exigir tal dedicación para el desempeño de otros órganos unipersonales de Gobierno. En ningún caso podrá ejercerse simultáneamente más de un cargo unipersonal de gobierno universitario.

3. Los Estatutos de la Universidad dispondrán los procedimientos para la evaluación periódica del rendimiento docente y científico del profesorado, que será tenido en cuenta en los concursos a que aluden los artículos 35 a 39, a efectos de su continuidad y promoción. En todo caso, las Administraciones competentes establecerán los mecanismos y procedimientos de evaluación de la calidad y el rendimiento de las Universidades en sus funciones docentes e investigadoras. 
Además, los departamentos elaborarán periódicamente una Memoria de su labor docente e investigadora, que será hecha pública por la Universidad en la forma que establezcan sus Estatutos.

13. El número 1 del artículo 46 y el número 3 que se añade al mismo quedan redactados como sigue:

"1. El Gobierno establecerá el régimen retributivo del profesorado funcionario universitario y de los cargos académicos, que tendrán carácter uniforme en todas las Universidades.

3. Las Comunidades Autónomas podrán equipar, con criterios objetivos las retribuciones del personal docente contratado a la de los funcionarios de los cuerpos docentes universitarios, teniendo en cuenta el itinerario formativo y profesional que para aquéllos hayan establecido. En todo caso, las retribuciones de los Profesores Contratados Doctores no podrán superar las previstas por la normativa vigente para los Catedráticos de Universidad.

14. El número 1 del artículo 47 y el actual número 4 que pasa a ser el 3 quedan redactados como sigue:

" 1. Cada Universidad establecerá anualmente en el estado de gastos de su presupuesto y en la liquidación de éste, su plantilla de profesorado, en la que se relacionarán debidamente clasificadas todas las plazas de profesorado, incluyendo al personal docente contratado, así como sus retribuciones, incluidas las percibidas por efecto de lo previsto en el artículo 11 de esta ley. 
3. La determinación en las plantillas del número de plazas que corresponde a cada categoría docente ha de guardar, en todo caso, la proporcionalidad que permita la realización de una carrera docente.

15. El artículo 48 queda redactado en la forma siguiente:

" Las Universidades establecerán fórmulas que permitan la permanente formación y adaptación de su profesorado a las necesidades docentes e investigadoras de aquéllas, pudiendo elaborar planes específicos de racionalización de sus recursos humanos."

16. La disposición adicional octava tendrá la siguiente redacción:

"A pesar de los dispuesto en el artículo 33, las Universidades podrán contratar con carácter permanente Profesores Asociados, entre nacionales de Estados No miembros de la Unión Europea".

17. Se añade una disposición adicional décima que tendrá la siguiente redacción:

"La participación de Profesores de reconocido prestigio con vinculación permanente a Universidades extranjeras, en las Comisiones juzgadoras de los concursos para plazas de los Cuerpos de Catedráticos de Universidad, Profesores Titulares de Universidad y Catedráticos de Escuelas Universitarias, será regulada por el Gobierno, previo informe del Consejo de Universidades."

18. Se añade una disposición adicional undécima que tendrá la siguiente redacción: 
"A los efectos de la concurrencia a los concursos previstos en los artículos 35 a 39 de la presente Ley y a las convocatorias de contratos de ayudante y de Profesor Asociado, Contratado Doctor y Colaborador, los nacionales de Estados miembros de la Unión Europea gozarán de idéntico tratamiento al de los nacionales españoles".

19. Se añade una disposición adicional duodécima que tendrá la siguiente redacción:

"A los Concursos de Méritos previstos en el apartado 2 del artículo 39 de la presente Ley podrán concurrir los profesores del Cuerpo al que corresponda la vacante que se hallen en situación administrativa de servicios especiales o de excedencia y que pretendan reingresar al servicio activo mediante su participación en el Concurso de Méritos."

20. Se añade una disposición adicional decimotercera que tendrá las siguiente redacción:

"La Alta Inspección garantizará el cumplimiento de las facultades atribuidas al Estado en materia de Enseñanza universitaria en las Comunidades Autónomas, y en las Universidades, en lo que al personal competencia del Estado se refiere, con la debida coordinación, en este último caso, con los servicios de la Comunidad Autónoma correspondiente y la observancia de los principios y normas constitucionales aplicables y los de esta Ley. Todo ello sin perjuicio de las competencias que las Comunidades Autónomas ostentan sobre las Universidades."

\subsection{Disposiciones adicionales}


Primera. Cuerpo de Maestros de Taller o Laboratorio y Capataces de Escuelas Técnicas.

Los funcionarios del Cuerpo de Maestros de Taller o Laboratorio y Capataces de Escuelas Técnicas, declarado a extinguir por la disposición transitoria quinta de la Ley Orgánica 11/1983, de 25 de agosto, modificada por la presente Ley, quedan integrados, en sus propias plazas, dentro del Cuerpo de Profesores Titulares de Escuelas Universitarias, siempre que no posean las condiciones de titulación exigidas para acceder a él. Quienes no se integran en éste último cuerpo, permanecerán en el de origen, sin perjuicio de su derecho a integrarse en el de Profesores Titulares de Escuelas Universitarias, siempre que, en el plazo de cinco años desde la entrada en vigor de la presente Ley, reúnan las antedichas condiciones de titulación.

Segunda. Referencias al antiguo Ministerio de Educación Ciencia.

Las referencias que se contienen en la Ley Orgánica 11/1983 de 25 de agosto, al Ministerio de Educación y Ciencia se han de entender hechas al Ministerio de Educación y Cultura.

\subsection{Disposiciones transitorias}

Primera. Adaptación de los Estatutos de las Universidades

1.- Las Universidades deberán adaptar sus Estatutos a lo previsto en la presente Ley en el plazo máximo de dos años tras su entrada en vigor. Hasta tanto se produzcan tales modificaciones estatuarias, las Juntas de Gobierno de las Universidades adoptarán las medidas necesarias para hacer posible la aplicación de la presente Ley. 
2.- La aplicación de esta Ley a las Universidades carentes de Estatutos, se efectuará mediante la potestad normativa de la Administración que ejerza la competencia sobre ellas.

3-. Transcurrido el plazo a que se refiere el apartado 1 de la presente disposición transitoria sin que una Universidad hubiere presentado para aprobación la adaptación de sus Estatutos, el Consejo de Gobierno de la correspondiente Comunidad Autónoma o , en su caso, el Gobierno realizará tal adaptación de modo provisional.

Segunda. Situación de los actuales ayudantes.

1. Quienes a la entrada en vigor de la presente Ley se hallen contratados como ayudantes de Facultades y Escuelas Técnicas Superiores o de Escuelas Universitarias podrán permanecer en su misma situación hasta la extinción del contrato y de sus eventuales renovaciones, conforme a la legislación que les venía siendo aplicable. A partir de ese momento, podrán vincularse con la Universidad en alguna de las categorías de personal docente contratado conforme a lo establecido en la Ley Orgánica 11/1983, de 25 de agosto, modificada por la presente Ley, con exclusión de las de ayudante en que hubieran estado contratados con anterioridad a la entrada en vigor de la presente Ley.

2. En las convocatorias para contratación como Profesor contratado Doctor se considerará mérito el tener la condición de ayudante en la fecha de entrada en vigor de esta Ley, sin perjuicio de la evaluación prevista en el apartado 5 del artículo 33 de la Ley Orgánica 11/1983, de 25 de agosto, modificada por la presente Ley. 
Tercera. Adaptación de los Profesores Asociados a las nuevas categorías contractuales creadas por la presente Ley.

1. Los Profesores Asociados en el momento de entrar en vigor esta Ley podrán continuar en el desempeño de su función, con arreglo a la actual normativa, hasta la finalización de la vigencia de sus actuales contratos. A partir de ese momento sólo podrán ser contratados de nuevo conforme a lo establecido en la Ley Orgánica 11/1983, de 25 de agosto, modificada por la presente Ley, en los términos previstos en la misma.

En las convocatorias para contratación como Profesor contratado Doctor se considerará mérito el tener la condición de Profesor Asociado en la fecha de entrada en vigor de esta Ley, sin perjuicio de la evaluación prevista en el apartado 5 del artículo 33 de la Ley Orgánica 11/1983, de 25 de agosto, modificada por la presente Ley.

2. No obstante lo indicado en el número anterior, los Profesores Asociados permanentes de nacionalidad extranjera, incluidos los nacionales de otros Estados miembros de la Unión Europea, que a la fecha de entrada en vigor de la presente Ley desempeñen su trabajo con una vinculación de carácter laboral con la Universidad, se incorporarán a la modalidad de Profesor Asociado prevista en la disposición adicional octava de la Ley Orgánica 11/1983, de 25 de agosto, modificada por la presente Ley, manteniendo los derechos que tengan adquiridos.

Cuarta. Actividad docente de los actuales Profesores Titulares de Escuelas Universitarias. 
No obstante lo establecido en el apartado 1 del artículo 35 de la Ley Orgánica 11/1983, de 25 de agosto, modificada por la presente Ley, los Profesores Titulares de Escuelas Universitarias que, con anterioridad a la fecha a que se refiere la siguiente disposición transitoria, desempeñaren su actividad en enseñanzas conducentes a la obtención de los títulos de Licenciado, Arquitecto o Ingeniero Superior, o en áreas de conocimiento distintas de aquéllas a las que se refiere el artículo antes citado, podrán continuar con su mismo régimen de docencia, quedando adscritos al área de conocimiento a la que lo estuvieren en ese momento.

Quinta. Aplicación de las normas establecidas para los concursos convocados para proveer plazas de los Cuerpos de funcionarios docentes.

1. Las normas establecidas en los artículos 35 a 38 de la Ley Orgánica 11/1983, de 25 de agosto, modificada por la presente Ley, para el acceso a plazas de los Cuerpos de Catedráticos y Profesores Titulares de Universidad y de Catedráticos y Profesores Titulares de Escuelas Universitarias, se exigirán en todos los concurso que se convoquen a partir de los seis meses siguientes a la entrada en vigor de esta misma Ley.

2. Los concursos convocados antes de la fecha indicada en el número anterior, se realizarán con arreglo a las normas contenidas en el los artículos 35 a 38 de la Ley Orgánica 11/1983, de 25 de agosto, previamente a su modificación por la presente Ley.

\subsection{Disposición derogatoria}

Unica 
Quedan derogadas cuantas disposiciones de igual o inferior rango se opongan a lo dispuesto en la presente Ley.

\subsection{Disposiciones finales}

Primera. Habilitación para el desarrollo reglamentario.

Corresponde al Gobierno y al Ministro de Educación y Cultura, así como a las Comunidades Autónomas, dictar, en el plazo de un año y en el ámbito de sus respectivas atribuciones, las disposiciones necesarias para el desarrollo y aplicación de la presente Ley.

Segunda. Entrada en vigor.

Esta Ley entrará en vigor el misma día de su publicación en el "Boletín Oficial del Estado". 